\title{
Analysis on the Attitude of Medical Students Working in Rural Areas
}

\author{
Dan Bai \\ School of Clinical Medicine \\ Xi'an Medical University \\ Xi'an, China 710041
}

\author{
Jinning Jia \\ School of Clinical Medicine \\ Xi'an Medical University \\ Xi'an, China 710041
}

\author{
Bibo Liu \\ School of Clinical Medicine \\ Xi'an Medical University \\ Xi'an, China 710041
}

\begin{abstract}
The development of health care is not balanced in the city and the countryside because of the poor primary medical treatment in rural areas of China. The aim of this research is to understand the reason why students are unwilling to work at the rural medical institutions. Impact factors are analyzed and countermeasures are proposed. The research methods combine questionnaires and interviews; 869 medical students have been selected and investigated adopting stratified random sampling method. Results in this study: first, it is found that $86 \%$ of girls tend to stay away from the countryside. $98 \%$ of students who come from the city don't want to engage in rural medical work. In higher grades, the number of students who are unwilling to work in the rural medical institutions increases rapidly. However, there is no difference from every major specialty. Second, the attitude of students is mainly impacted by social factors. Third, the government should provide positive guidance to encourage students to engage in the rural medical services. Conclusion: not only health care system but also the career guidance should be improved to promote the sustainable development of society.
\end{abstract}

Keywords-medical students; rural medical work; sustainable development

\section{INTRODUCTION}

At present, it is universally true that the global distribution of medical resources between urban and rural areas is not balanced. Back in 2010, WHO addressed that approximately one-half of the world population lived in rural area while less than a quarter of physicians worked in remote and rural area despite adequate absolute number of physicians in some low-income countries[1]. Furthermore, World Health Organization estimates that more than 4 million health workers are needed to fill the health workforce gap globally. This includes 2.4 million physicians, nurses and medical technicians [2]. Thus, in China with a large rural

*Fund: This work was supported in part by the fund of the "13th FiveYear Plan" education science project of Shaanxi province [Project No.SGH18H439] and fund of Xi'an Medical University. Project No. 2018PT35 population, it is much important to cultivate the professiona personnel for the development of rural basic health service.

As an integral part of rural construction, rural health work plays an important role in rural reconstruction. In five countries in Asia, including China, the attitude of working in rural area and self-assessment of competencies are conducted [3]. It not only covers first- and second-year medical students who have just entered the school, but also discusses the medical students who are about to graduate [4]. It is needed to learn the willingness of medical students to work in rural areas [5]. For example, cross-sectional descriptive studies about the factors which influence the choice of urban or rural location for future practice of Nepalese medical students [6]. Study of meeting the future health care needs of rural communities for a sustainable workforce in Australia has been addressed in [7].

With the cognition of the reason why students are unwilling to serve at the rural medical institutions, it is needed to analyze influencing factors and put forward corresponding solutions to promote the sustainable development of rural grassroots health works in the future China.

\section{METHODS}

\section{A. Participants}

A standard questionnaire was mailed to a randomly selected sample of 869 persons in February, 2018. The invalid questionnaires with poor completeness or contradictory answers were eliminated and the actual valid questionnaires were 832. The effective rate of questionnaires was $95.7 \%$. 28 students were interviewed.

\section{B. Questionnaire}

Among the respondents, interviews were also conducted among students in every grade of Xi'an Medical University. Questionnaires designed for anonymous response comprised 
of 18 questions. These questions can be divided into seven parts with regard to their purposes:

Questions 1 to 4 are about the basic situation of medical students and their attitude towards rural medical work. Questions 5-6 are related to the working environment of primary health care and current government measures from a social point of view. From the university point of view, Questions 7-10 consider the hospital level during the clinic practice and afterward working environment in contrast to the rural medical institutions, and the degree of indications from professors of working in a modern hospital that is usually locating in the urban area. Questions 11 to 12 are about the family background, since parents blindly inculcate the idea to their children that a higher platform is good for career development and can be used to exude in front of friends and family. Questions 13 to 15 began with the hope of changing the economic situation of the family through their own efforts and becoming professional with the development of their own. Questions 16 to 17 investigate the attitude of medical students towards the development of rural health care in the future. Particularly, only the interviewers can submit the above mentioned questionnaires.

\section{RESULTS}

Xi'an Medical University orients the rural medical health care. It is a unique university in Xi'an area, which provides great concerns on the medical and health care in rural areas. Thus, the survey was conducted on campus. "Table I" lists the attitude of the students in Xi'an Medical University towards working at the grass-roots level from the aspects of gender, household registration type, grade and even specialty. It shows that medical students generally do not like primary care. $86.0 \%$ girls tend to stay away from the countryside. $98.0 \%$ students who come from the city don't want to engage in rural medical work. In higher grades, the number of students who are unwilling to serve at the rural medical institutions rapidly increases. However, there is no significant difference between the main specialties.

TABLE I. RESPONDENTS’ ATtITUDE TOWARD RURAL MEDICAL WORK

\begin{tabular}{|l|l|l|l|}
\hline \multicolumn{2}{|c|}{ Project } & \multicolumn{1}{c|}{$\begin{array}{c}\text { Willingness } \\
\text { Number /Percentage }\end{array}$} & $\begin{array}{c}\text { Reluctance } \\
\text { Number /Percentage }\end{array}$ \\
\hline \multirow{2}{*}{ Sexuality } & boys & $79 / 27.9 \%$ & $204 / 72.1 \%$ \\
\cline { 2 - 4 } & girls & $73 / 14.0 \%$ & $448 / 86.0 \%$ \\
\hline \multirow{3}{*}{ Household type } & city & $10 / 2.1 \%$ & $468 / 97.9 \%$ \\
\cline { 2 - 4 } & rural & $113 / 34.7 \%$ & $213 / 65.3 \%$ \\
\hline \multirow{5}{*}{ Grade } & fresh man & $98 / 60.9 \%$ & $63 / 39.1 \%$ \\
\cline { 2 - 4 } & sophomore & $75 / 46.6 \%$ & $86 / 53.4 \%$ \\
\cline { 2 - 4 } & junior & $72 / 45.0 \%$ & $88 / 55.0 \%$ \\
\cline { 2 - 4 } & senior & $69 / 42.9 \%$ & $92 / 57.1 \%$ \\
\cline { 2 - 4 } & graduate & $43 / 26.7 \%$ & $118 / 73.3 \%$ \\
\hline \multirow{3}{*}{ Specialty } & clinical medicine & $101 / 37.7 \%$ & $152 / 62.3 \%$ \\
\cline { 2 - 4 } & nurse & $116 / 43.3 \%$ & $156 / 58.7 \%$ \\
\cline { 2 - 4 } & medical technicians & $112 / 41.8 \%$ & \\
\hline
\end{tabular}

"Table II" shows that some students $(30.7 \%)$ think that society plays a vital role in the rural health work of medical students. Some medical students think that schools $(19.7 \%)$ and families $(23.1 \%)$ exert a subtle influence on students. To some extent, individuals $(26.5 \%)$ are also influenced by the environment and form a sense of distance from rural medical care.

\section{TABLE II. Factors PREVENTING MEDical StUdents ENGAGE IN} RURAL MEDICAL WORK

\begin{tabular}{|l|l|}
\hline \multicolumn{1}{|c|}{ Factors } & Number/Percentage \\
\hline Social & $247 / 30.7 \%$ \\
\hline School & $158 / 19.7 \%$ \\
\hline Family & $186 / 23.1 \%$ \\
\hline person & $213 / 26.5 \%$ \\
\hline
\end{tabular}

Society: People in the society are still unable to accept medical students who are engaged in basic health care. The rural medical work environment is monotonous and the lack of government input makes many medical students consider that if they work at the grass-roots level, they will be regarded as the ones that have less ability to obtain a respectable job in the urban area.

School: Students are encouraged to work in tertiary hospitals and the education of students engaged in rural primary health care is the same in essentials while differing in minor points as that of other students.

Family: Parents, influenced by traditional concepts and restricted by family economic conditions, support their children to stay away from rural primary health care.

Person: They have high demands on themselves and are not satisfied with the current situation. Some students hope to have a better platform and get quality development.

"Table III" investigates the views of medical students on the future development of primary health work. Some people $(62.4 \%)$ think that it will develop in a better direction, some think $(25.8 \%)$ that there will not be too much change, and others believe $(11.8 \%)$ that the gap between urban and rural areas will widen. Their choices also change with the development of society. 
TABLE III. The VIEW of Medical Students on the Future Development

\begin{tabular}{|l|l|l|l|}
\hline & \multicolumn{1}{|c|}{$\begin{array}{c}\text { Positive } \\
\text { Number/Percentage }\end{array}$} & $\begin{array}{c}\text { Negative } \\
\text { Number/Percentage }\end{array}$ & $\begin{array}{c}\text { Neutral(no attitudes) } \\
\text { Number/Percentage }\end{array}$ \\
\hline Attitude & $502 / 62.4 \%$ & $95 / 11.8 \%$ & $207 / 25.8 \%$ \\
\hline Countermeasures & $458 / 57.0 \%$ & $121 / 15.0 \%$ & $225 / 28.0 \%$ \\
\hline
\end{tabular}

The interviews conducted among the medical students confirm their attitudes toward rural health work. If they engage in rural medical work, other people will think they are not good students. Thus, they strongly refuse this job. This is similarly to the results of the questionnaire.

However, this paper has been impressed by the words of a medical student from junior level.

"Although working at the rural medical work is not the first choice for medical students, it is believed that through the joint efforts of all, the number of medical students that tend to work at the rural medical institutions will be increasing. They serve the broadest masses and realize their original medical dream. It is proud to be a man who can save lives and realize the value of doctors."

\section{DISCUSSION}

The purpose of this study is to understand the factors that affect the reluctance of medical students to engage in rural primary care. There are still many internal and external problems in rural health work, such as the imperfection of the social system, the vision of the people around them, and the values of their own, which prevent the sustainable development of primary medical service in our country.

The study finds that medical students' attitude toward the medical and health work for rural medical care will be also changed with the development in future society. They are willing to help them, as Dr. Trudeau says "To Cure Sometimes, To Relieve Often, To Comfort Always". It is not easy for the civilians to see doctors and the number of doctors in the hospital is not sufficient. Some common diseases can be cured in primary hospitals. In a word, it alleviates the burden of large hospitals and makes full use of medical resources.

The method is constrained to the questionnaire quantity. The respondents, as the interviewees, are mainly composed of young adults. Hence the results of the study should be treated with caution. Further research is recommended to analyze, on a larger and more balanced scale, the factors that influence medical students' reluctance to engage in rural medical work.

In addition to changing the provision of lower scores to students in rural primary health care or setting up general practice medicine, an ambient circumstance is also created through the strength of the public, to solve the problems existing at the grass-roots level. Through this kind of synergetic effect, it is available to find a new way of Chinese characterized rural medical health care.

After understanding the present situation of the rural medical health care in China, it is helpful to improve the policy, change the concept of basic health service and contribute to the introduction of talents, and change the current situation of the lack of medical personnel in rural health care. The goal of sustainable development will be realized.

\section{CONCLUSION}

This paper studies the attitude of medical university students through questionnaires and interviews. Most of the students are not willing to work for rural health care due to various influences from the society, family and personal reasons, although it is quite necessary to increase the number of doctors in rural medical institutions. However, from this study, it is found that with the change in the perceptive of rural medical health care, and rapid development of infrastructure, more aspirant medical students will involve working in the rural medical health care.

\section{REFERENCES}

[1] Organization WH.(2010). "Increasing access to health workers in remote and rural areas through improved retention: Global policy recommendations", Contract No.: 9789241564014.

[2] Chen L, Evans T, Anand S, Boufford Joe I, Brown H, Chowdhury M, Cueto M, Dare L, Dussault G, Elzinga G, Fee E, Habte D, Hanvoravongchai P, Jacobs M, Kurowski C, Michael S, PablosMendez A, Sewankambo N, Solimano G, Stilwell B, de Waal A Wibulpolprasert S.(2004). "Human resources for health: overcoming the crisis." Lancet, 364:1984-90.

[3] Wanicha L. Chuenkongkaew, Himanshu Negandhi, Pisake Lumbiganon, Weimin Wang, Kawkab Mahmud and Pham Viet Cuong (2016). "Attitude towards working in rural area and selfassessment of competencies in last year medical students: A survey of five countries in Asia", Chuenkongkaew et al. BMC Medical Education 16:238.

[4] P Ravi Shankar and Trilok P Thapa. (2012). "Student perception about working in rural Nepal after graduation: a study among firstand second-year medical students", Shankar and Thapa Human Resources for Health, 10:27.

[5] Peter Agyei-Baffour, S Rani Kotha, Jennifer C Johnson, Mawuli Gyakobo, Kwesi Asabir, Janet Kwansah, Emmanuel Nakua, Mawuli Dzodzomenyo, Rachel C Snow and Margaret E Kruk. (2011). "Willingness to work in rural areas and the role of intrinsic versus extrinsic professional motivations- a survey of medical students in Ghana", Agyei-Baffour et al. BMC Medical Education, 11:56.

[6] Bhim Prasad Sapkota and Archana Amatya. (2015). "What factors influence the choice of urban or rural location for future practice of Nepalese medical students? A cross-sectional descriptive study", Sapkota and Amatya Human Resources for Health. 13:84.

[7] M. Hay, A. M. Mercer, I. Lichtwark, S. Tran, W. C. Hodgson, H. T. Aretz, E. G. Armstrong, D. Gorman. (2017). "Selecting for a sustainable workforce to meet the future health care needs of rural communities in Australia", Adv in Health Sci Educ. 22:533-551. 